\title{
Reprodução Induzida da Piabanha, Brycon insignis (Steindachner, 1876), Mantida em Cativeiro*
}

\section{Elaine Fender de Andrade-Talmelli ${ }^{1}$, Emico Tahira Kavamoto1, Massuka Yamane Narahara1, Nelsy Fenerich-Verani ${ }^{2}$}

\begin{abstract}
RESUMO - Estudos de reprodução induzida da piabanha, Brycon insignis, foram realizados em janeiro-fevereiro/96 e fevereiro/97, utilizando-se exemplares de 3 a 5 anos de idade, mantidos em cativeiro na Estação Experimental da Seção de Hidrobiologia e Aqüicultura, pertencente à CESP (Companhia Energética de São Paulo), localizada na cidade de Paraibuna, SP. As fêmeas selecionadas para indução da reprodução apresentaram ventre abaulado, papila genital saliente e avermelhada e $60 \%$ dos ovócitos com núcleo em posição excêntrica. Trinta e três fêmeas foram induzidas à reprodução com dose única de hCG de 5 UI/g (gonadotropina coriônica humana); 17 receberam duas aplicações de extrato bruto de hipófise de carpa, de 0,5 e 5,0 mg/kg, com intervalo de 10 horas entre as aplicações; 18 receberam $0,5 \mathrm{mg} / \mathrm{kg}$ de extrato bruto de hipófise de carpa e, após 10 horas, $5 \mathrm{UI} / \mathrm{g}$ de hCG; 5 fêmeas receberam dose única de solução salina a $0,9 \%$. Cerca de 10 horas após a última aplicação hormonal, 43 fêmeas responderam positivamente aos tratamentos hormonais liberando óvulos por extrusão. A distribuição de freqüência porcentual dos diâmetros dos ovócitos da amostra inicial apresentou tendência unimodal, com moda em $1250 \mu \mathrm{m}$. Entre os hormônios testados, o mais eficiente foi o hCG, em dose única, e o menos eficiente, o de hipófise de carpa, com aplicação de duas doses. Os machos receberam dose única de 3 UI de hCG/g. Cada fêmea liberou, em média, 24.690 óvulos, que, após a fertilização e hidratação, se apresentaram esféricos, demersais e não adesivos, com diâmetro médio de 3785 a 3900 m, grande espaço perivitelínico e córion resistente. A taxa de fertilização oscilou entre 20 e $96 \%$ e a de eclosão, entre 0 e $85 \%$. A temperatura da água foi de $26^{\circ} \mathrm{C} \pm 1^{\circ} \mathrm{C}$.
\end{abstract}

Palavras-chave: Brycon insignis, peixe de água doce, piabanha, reprodução induzida

\section{Induced Spawning of "Piabanha" (Brycon insignis Steindachner, 1876) in Captivity}

ABSTRACT - Studies of induced spawning of piabanha, Brycon insignis, were developed from January to February/96 and February/97, with 3 to 5 years old individuals maintained in captivity. The selected females presented swollen abdomen and red genital papilla, $60 \%$ of oocytes with eccentric germinal vesicle. Thirty-three females were induced to spawning through a single dose of 5 IU/ $\mathrm{g}$ of hCG (human Chorionic Gonadotropin); 17 females received two application: 0.5 and $5 \mathrm{mg} / \mathrm{kg}$ of crude carp pituitary extract in an interval of 10 hours; 18 received one application of $0.5 \mathrm{mg} / \mathrm{kg}$ of crude carp pituitary extract and, after $10 \mathrm{hours}, 5 \mathrm{IU} / \mathrm{g}$ of hCG; and 5 females received a single dose of $0.9 \%$ saline solution. About 10 hours after the last hormonal application, 43 females responded positively to the hormonal treatment releasing eggs by extrusion. The percent frequency distribution of the oocytes diameter in the initial sample presented unimodal tendency, with mode in $1250 \mu \mathrm{m}$. Considering the different hormones utilized, the most efficient was hCG in a single dose and the less efficient was the hormone of carp pituitary applicated in two doses. The males received one dose of 3 IU/ $\mathrm{g}$ of hCG. The females released a mean of 24,690 eggs, wich after fertilization and hydration presented an sphere form, were demesal and non-adhesive, with mean diameter from 3785 to $3900 \mu \mathrm{m}$, and had an expressive perivitelin space and a hard chorion. The rate of fertilization ranged from 20 to $96 \%$ and that of hatching, from 0 to $85 \%$. The water temperature was $26^{\circ} \mathrm{C} \pm 1{ }^{\circ} \mathrm{C}$.

Key Words: Brycon insignis, fresh water fish, "piabanha", induced spawning

\section{Introdução}

O gênero Brycon (Characiformes, Characidae, Bryconinae) compreende mais de 60 espécies de peixes com ampla distribuição geográfica (Fowler, 1950). De acordo com Lima \& Britski (1997), a sistemática do grupo é extremamente confusa, e o gênero provavelmente não é monofilético.

No Brasil, vêm sendo realizados trabalhos com o matrinxã, Brycon cephalus, da Bacia Amazônica (Howes, 1982), visando conhecer o comportamento da espécie em confinamento (Bernardino et al., 1993;

\footnotetext{
* Parte da Dissertação de Mestrado da primeira autora. Projeto financiado pela CAPES (Coordenadoria de Aperfeiçoamento de Pessoal de Nível Superior) e IP/SAA (Instituto de Pesca - Secretaria de Agricultura e Abastecimento do Estado de São Paulo)

${ }^{1}$ Pesquisador Científico - Centro de Pesquisa em Reprodução e Larvicultura - Instituto de Pesca/SAA, Av. Francisco Matarazzo, 455, Água Branca-SP - CEP-050001-900. E.mail: etalmelli@ig.com.br; mnarahara@ig.com.br

${ }^{2}$ Prof ${ }^{a}$ Dra. Departamento de Hidrobiologia - Universidade Federal de São Carlos - UFSCar, Rodovia Washington Luiz km 235. CEP-13565-905. E.mail: dnfv@power.ufscar.com.br
} 
Mendonça, et al., 1993; Mendonça, 1994; Pereira Filho et al., 1994; Romagosa, 1998). A piracanjuba, Brycon orbignyanus, e o matrinchã,Brycon lundii, da Bacia do São Francisco, e a pirapitinga-do-sul, Brycon opalinus, da Bacia do Paraíba, têm sido alvo de pesquisas de comportamento biológico e reprodução induzida (Belmont, 1994; Piovesan et al., 1994; Lima et al., 1995; Sato et al., 1997; Narahara et al., 1986, 1987, 1988 e 1994; Girardi et al., 1995).

A piabanha (Brycon insignis Steindachner, 1876) é uma espécie nativa e exclusiva do Rio Paraíba do Sul (Fowler, 1950), no Estado de São Paulo. Segundo Machado \& Abreu (1952), foi considerada a $4^{\mathrm{a}}$ espécie de peixe mais capturada pela pesca comercial na década de 50, atingindo elevado valor no mercado consumidor da região. Segundo os mesmos autores, o Rio Paraíba do Sul constituía-se em um dos mais piscosos do Estado, porém a maioria das espécies era considerada de qualidade inferior, com exceção de piabanha, piavas e surubim-do-paraíba. Diversos fatores influenciaram a redução dos estoques da piabanha para níveis críticos em seu ambiente natural: desmatamento ciliar, provocado pelo incremento da atividade agrícola, drenagem das várzeas para o cultivo de arroz no trecho do Rio Paraíba entre as cidades de Guararema e Cachoeira Paulista, trecho esse considerado como "berçário" para larvas e alevinos, a poluição do rio, ocasionada pelo lançamento de resíduos industriais e domésticos, alterando a composição física e química da água, e a introdução do voraz dourado (Salminus maxillosus) em suas águas (Salgado et al., 1997). O barramento do Rio Paraíba, para construção da usina hidrelétrica de Paraibuna-Paraitinga, foi fator de relevante importância para a alteração do comportamento e sobrevivência da piabanha (Salgado et al., 1997). Embora a construção de usinas hidrelétricas tenha trazido benefícios econômicos para a região, transformou ambientes lóticos em lênticos, modificando o rítmo migratório das espécies reofílicas. Sendo a piabanha espécie de piracema (migradora reprodutiva), os barramentos no Rio Paraíba provocaram drástica redução de seu estoque, e atualmente há grande dificuldade de captura desse peixe no ambiente natural (Salgado et al., 1997).

A obtenção de larvas e alevinos de espécies migradoras depende, entre outros fatores, da utilização de métodos de propagação artificial. Em 1989, foram realizados os primeiros experimentos de indução da reprodução de piabanha, utilizando extrato de pituitária de salmão (EPS) associado a hCG (Gonadotropina Coriônica humana) e extrato de hipófise de carpa comum (EHC) acrescido de plasil, com a obtenção de pequena produção. No segundo, terceiro e quarto experimentos, foi utilizado somente EHC, acrescido de plasil, obtendo-se 1.800 alevinos $(22,55 \%$ de sobrevivência) (Girardi et al., 1993; Salgado et al., 1997).

Em virtude das escassas informações sobre o comportamento biológico da piabanha (Brycon insignis) em seu hábitat natural, para que os programas de povoamento e repovoamento tenham sucesso, é necessário o aprimoramento das técnicas de indução da reprodução, identificando o momento propício para a utilização de hormônios indutores e definindo a dosagem de hormônio e o período de latência para obtenção de maior número de larvas e alevinos de boa qualidade. Estas informações poderão nortear novos experimentos, melhorando as condições de cultivo, valorizando a atividade no sentido econômico, assim como aumentando o número de alevinos destinados à preservação desta espécie.

Objetivou-se, com o presente estudo, estabelecer o momento ideal para a indução da reprodução em fêmeas de Brycon insignis, associando-se características externas às internas, e verificar os efeitos do hCG (Gonadotropina Coriônica humana) em dose única, de hCG combinado com EHC (extrato bruto de hipófise de carpa) e EHC em duas doses, como agentes indutores da reprodução.

\section{Material e Métodos}

O trabalho experimental foi desenvolvido na Estação Experimental de Hidrobiologia e Aqüicultura, pertencente à CESP (Companhia Energética de São Paulo), localizada no município de Paraibuna, Estado de São Paulo.

Foram utilizados reprodutores de piabanha, Brycon insignis, com 3, 4 e 5 anos de idade, mantidos em viveiros de $600 \mathrm{~m}^{2}$, com fundo de terra, na densidade de 1 peixe $/ \mathrm{m}^{2}$.

A alimentação fornecida foi ração balanceada, com $35 \%$ de proteína bruta, oferecida duas vezes ao dia, em três dias da semana, na proporção de $5 \%$ do peso total dos peixes.

Em dezembro de 1995 foi examinado o grau de desenvolvimento das gônadas de seis machos e seis fêmeas e definida a época de início dos trabalhos.

Em janeiro-fevereiro/96 e fevereiro/97, 100 fê- 
meas foram avaliadas para participarem do processo de indução reprodutiva. Os exemplares foram retirados do viveiro com rede de arrasto e transportados vivos até o laboratório. Após a anestesia individual dos peixes em 10 litros de solução de mentol, a uma concentração de 100 ppm, anotaram-se dados de comprimento total, em centímetro e peso total, em grama; sendo a seguir colocados em aquários experimentais dos quais se registrou diariamente o valor da temperatura da água.

Dentre as cem fêmeas avaliadas, selecionaramse 73 , que apresentavam ventre abaulado e papila genital saliente e avermelhada. Dessas fêmeas, o comprimento total variou de 28,5 a 37,5 centímetros (média de 33,2 $\pm 1,9 \mathrm{~cm}$ ) e o peso total, de 288,0 a 635,0 gramas (média de 410,6 $\pm 81,8 \mathrm{~g}$ ).

De cada fêmea foram retiradas 2 amostras iniciais de ovócitos intra-ováricos, com auxílio de cânula plástica, introduzida pela papila genital. As amostras foram avaliadas quanto à homogeneidade dos ovócitos em tamanho e cor, e facilidade de obtenção dos mesmos. O grau de desenvolvimento dos ovários foi verificado através da análise do padrão de distribuição de freqüência porcentual dos diâmetros dos ovócitos (Fenerich-Verani et al., 1984), da seguinte forma: uma das amostras foi fixada em solução de Gilson modificada (Simpson, 1951) por 30 minutos, e os ovócitos, medidos com auxílio de ocular micrométrica (10x), sob microscópio estereoscópico ZEISS (obj. 2x). As freqüências porcentuais destes diâmetros foram calculadas e lançadas em gráfico. Calcularam-se, ainda, para cada amostra, os diâmetros médios dos ovócitos. A outra amostra foi fixada em líquido de Serra (Lemanova \& Sakun, 1975) para permitir a visualização da vesícula germinativa, ou núcleo, sendo o exame realizado imediatamente após a fixação. Foram consideradas três categorias de ovócitos: com núcleo em posição central, com núcleo em posição excêntrica e com núcleo não visível.

Os tratamentos testados foram: Tratamento I: 33 fêmeas receberam hCG (Gonadotropina Coriônica humana-Pregnyl /Organon do Brasil) em dose única $5 \mathrm{UI} / \mathrm{g}$ de peso; Tratamento II: 18 fêmeas receberam extrato bruto de hipófise de carpa diluído em solução salina $0,9 \%$ : 1a dose de $0,5 \mathrm{mg} / \mathrm{kg}$ e $2-$ a dose de 5,0 $\mathrm{mg} / \mathrm{kg}$, com intervalo de 10 horas entre as aplicações; Tratamento III: 17 fêmeas receberam: â dose de extrato bruto de hipófise de carpa, diluído em solução salina $0,9 \%$, na proporção de $0,5 \mathrm{mg} / \mathrm{kg}$, e 2 a dose de hCG (Gonadotropina Coriônica humana), na propor- ção de 5 UI de hCG/g com intervalo de 10 horas entre as aplicações; Tratamento IV: Controle -5 fêmeas receberam aplicação de $1,0 \mathrm{~mL}$ de solução salina a $0,9 \%$, em dose única.

Os machos selecionados, em número de 50 , foram aqueles cujo sêmen era liberado sob leve compressão da região abdominal. Estes exemplares que apresentavam comprimento total médio de 29,3 $\pm 1,8$ $\mathrm{cm}$ e peso total médio de $229,3 \pm 45,8 \mathrm{~g}$, receberam $3 \mathrm{UI} / \mathrm{g}$ de hCG, 6 horas antes do momento da segunda aplicação nas fêmeas dos tratamentos II e III, e antes da única aplicação nas fêmeas do tratamento I.

Os exemplares anestesiados receberam as aplicações hormonais intraperitoniais. Após a aplicação, cada fêmea foi mantida em aquário individual de 1000 litros, e os machos, distribuidos em 4 caixas de cimento com capacidade de 2000 litros cada uma, com aeração e renovação de água constantes. A temperatura da água dos aquários variou entre $25 \mathrm{e}$ $27^{\circ} \mathrm{C}$. Aproximadamente 10 horas após a aplicação hormonal, observou-se a liberação de óvulos por algumas fêmeas, as quais foram retiradas e cuidadosamente secas com auxílio de toalha para, a seguir ser realizada a extrusão dos óvulos. Estes foram pesados, em grama, para estimativa do número total de óvulos liberados por fêmea. A fertilização "a seco", segundo von Ihering \& Azevedo, 1934, foi feita com cerca de 1,0 mL de sêmen. Óvulos, sêmen e água foram misturados durante 5 minutos e, posteriormente, realizadas duas trocas de água para retirada do sêmen excedente. Em seguida, cada fêmea teve seus ovos colocados, separadamente, em incubadoras cônicas de fibra de vidro, com capacidade de 60 e 250 litros e renovação de água constante, a uma vazão de 30 e 50 litros/minuto, respectivamente.

Para a estimativa do número total de óvulos liberados, foi feita a contagem do número de células contidas em 1 grama, e o cálculo das taxas de fertilização e de eclosão das larvas foi realizado segundo Andrade-Talmelli (1997).

\section{Resultados e Discussão}

Em dezembro de 1995, no início os trabalhos experimentais, foi avaliado o grau de desenvolvimento das gônadas dos reprodutores de piabanha. Observou-se que os machos liberavam sêmen com facilidade sob leve compressão do abdômen no sentido ântero-posterior. As fêmeas, apesar da região abdominal bastante dilatada, não apresentavam caracte- 
rísticas externas bem evidentes como papila genital avermelhada e protuberante. Os ovócitos, retirados do ovário com uso de cânula, apresentavam-se em grumos, indicando, portanto, não ser o momento para a indução reprodutiva. Pela análise da distribuição de frequiência porcentual dos diâmetros dos ovócitos, em cada fêmea, verificou-se que o diâmetro de maior frequiência oscilou entre 1150 e $1200 \mu \mathrm{m}(1175 \pm 27 \mu \mathrm{m})$. Quanto à posição do núcleo, 100\% dos ovócitos apresentavam-no em posição central.

Em janeiro e fevereiro/96 e fevereiro/97, os ovócitos, retirados facilmente através de canulação, apresentavam coloração esverdeada, principalmente entre verde-escura e verde-acastanhada. Quanto à posição do núcleo, a maioria das fêmeas apresentava-no $60 \%$ excêntrico e $40 \%$ central.

Observando os resultados apresentados na Tabela 1 , nota-se que, entre os tratamentos testados, o que propiciou o maior número de respostas positivas foi o Tratamento I, com 81,8\% das fêmeas respondendo à indução. Com o tratamento II, responderam positivamente apenas $27,8 \%$ das fêmeas e com o tratamento III, $64,7 \%$ das fêmeas. O tratamento IV foi realizado como controle, não sendo obtida nenhuma resposta.

Desde a década de 30 , pesquisas vêm sendo conduzidas visando à obtenção de desova induzida em peixes; a primeira foi realizada por von Ihering \& Azevedo (1934), denominada "hipofisação". Esta técnica foi amplamente difundida e aperfeiçoada, porém apresentava problemas ligados à dosagem para induzir a reprodução e à potência gonadotrópica da hipófise do doador. Além disso, a técnica é criticada por se tratar de um extrato que contém, de uma única vez, toda a gama de hormônios sintetizados pela hipófise (Kuo \& Nash, 1975; Jalabert et al., 1977; Harvey \& Hoar, 1980; Lam, 1982). Entretanto, a hipofisação apresenta vantagens: não requer aquisição de equipamento sofisticado; a dosagem do hormônio é calculada com base no peso total do exemplar a ser induzido (receptor) e o preço é menor em relação aos outros hormônios disponíveis no mercado. Dessa forma, continua a ser largamente utilizada na América do Sul como método preferencial para induzir a desova de espécies de peixes reofílicos (Harvey \& Carolsfeld, 1993).

O hCG (Gonadotropina Coriônica humanaPregnyl) é um potente indutor da reprodução em peixes e apresenta a vantagem da certeza da igualdade das dosagens, de poder induzir a maturação final, ovulação e espermiação. Diversas pesquisas demonstraram a efetividade desse hormônio na obtenção da reprodução de espécies de peixes nativos e de interesse comercial (Fenerich et al., 1974, em Rhamdia hilarii, Pimelodus maculatus e Salminus maxillosus; Romagosa et al., 1990, em Piaractus mesopotamicus; Antoniutti et al., 1995, em Prochilodus scrofa).

German (1994) verificou que o uso da combinação de diferentes hormônios tem sido comum, visando otimizar os resultados. Segundo Lam (1982), a

Tabela 1 - Taxas de resposta positiva (ovulação) de piabanha, Brycon insignis, submetida a diferentes tratamentos hormonais

Table 1 - Positive reaction (ovulation) rates of piabanha, Brycon insignis, submitted to different hormonal treatments

\begin{tabular}{|c|c|c|c|c|c|}
\hline \multirow[t]{3}{*}{$\begin{array}{l}\text { Tratamento } \\
\text { Treatment }\end{array}$} & \multirow[t]{3}{*}{$\begin{array}{l}\text { № de fêmeas utilizadas } \\
\quad N \text {. offemales used }\end{array}$} & \multicolumn{4}{|c|}{$\begin{array}{l}\text { Resposta } \\
\text { Response }\end{array}$} \\
\hline & & \multicolumn{2}{|c|}{$\begin{array}{l}\text { Positiva } \\
\text { Positive }\end{array}$} & \multicolumn{2}{|c|}{$\begin{array}{l}\text { Negativa } \\
\text { Negative }\end{array}$} \\
\hline & & $\mathrm{N}$ & $\%$ & $\mathrm{~N}$ & $\%$ \\
\hline $\begin{array}{l}\mathrm{I}-\mathrm{hCG} \text { dose única } \\
I-h C G \text { single dose }\end{array}$ & 33 & 27 & 81,8 & 06 & 18,2 \\
\hline $\begin{array}{l}\text { *II - extrato bruto de hipófise de carpa ( } 2 \text { doses }) \\
* I I-\text { crude carp pituitary extract }(2 \text { doses })\end{array}$ & 18 & 05 & 27,8 & 13 & 72,2 \\
\hline $\begin{array}{l}\text { *III - extrato bruto de hipófise de carpa e hCG } \\
\text { *III - crude carp pituitary extract and hCG }\end{array}$ & 17 & 11 & 64,7 & 06 & 35,3 \\
\hline $\begin{array}{l}\text { IV - solução salina } \\
\text { IV - saline solution }\end{array}$ & 5 & - & - & - & - \\
\hline Total & 73 & 43 & - & 25 & - \\
\hline
\end{tabular}

*Intervalo de 10 horas entre as aplicações.

* Interval of 10 hours between applications.

R. Bras. Zootec., v.31, n.2, p.803-811, 2002 (suplemento) 
utilização de gonadotropina associada a extratos hipofisários parece ser o método mais freqüente para potencializar a ação hormonal nas gônadas, sendo tradicionalmente aplicado em 2 doses.

Zaniboni Filho \& Barbosa (1996) testaram a aplicação de dose "priming" de $0,25 \mathrm{mg}$ de extrato bruto de hipófise de carpa $/ \mathrm{kg}$ de peso total em fêmeas de diversas espécies tropicais de peixes. O tratamento foi aplicado 1 a 3 dias antes do tratamento convencional $(0,5$ e $5 \mathrm{mg}$ de extrato bruto de hipófise $/ \mathrm{kg})$. Outros hormônios também foram testados, como: 1,5 e $15 \mathrm{~mm}$ de LH-RH-a/kg ou dose única de LH-RHa de $10 \mathrm{~mm} / \mathrm{kg}$. Os resultados mostram que com a utilização da dose "priming", maior número de fêmeas respondeu aos tratamentos hormonais.

A piabanha perde escamas com facilidade durante o manejo; desta forma, não foi testada a dose "priming", por considerar-se que maior manipulação dos reprodutores aumentaria o estresse com possíveis interferências na resposta aos tratamentos hormonais.

Pela análise das distribuições de freqüência porcentual dos diâmetros dos ovócitos de Brycon insignis, foi possível verificar que as 43 fêmeas que responderam positivamente aos tratamentos hormonais apresentaram, na amostra inicial, distribuições com tendência unimodal. Observou-se que o diâmetro de maior freqüência foi igual a $1250 \mu \mathrm{m}$ (Figuras $1 \mathrm{~A}$ e B) e que o diâmetro médio variou entre 1222 e $1307 \mu \mathrm{m}$.

No momento da extrusão (ovulação), os valores do diâmetro de maior frequiência foram de 1450 (ovócitos verde-escuros) e $1500 \mu \mathrm{m}$ (ovócitos verde-acastanhados) (Figura $1 \mathrm{~A}$ e B).

Esses resultados permitem supor que durante o processo de maturação gonadal ocorra desenvolvimento ovocitário do tipo sincrônico em grupos (Wallace \& Selman, 1981), possibilitando utilizar o padrão de distribuição de freqüência porcentual dos diâmetros dos ovócitos como indicador do grau de desenvolvimento dos ovários (Greeley Jr. et al., 1987; West, 1990).

Esses resultados corroboram aqueles obtidos por Fenerich-Verani et al. (1984) que verificaram entre as fêmeas de curimbatá, Prochilodus scrofa, distribuição de frequiência porcentual dos diâmetros dos ovócitos com moda igual a $1111 \mu \mathrm{m}$ e tendência unimodal. Bernardino et al. (1993) verificaram que as fêmeas de matrinchã, Brycon cephalus, responderam positivamente à indução hormonal quando apresentavam ovócitos verdes, homogêneos em tamanho e cor, com diâmetro médio da amostra inicial igual a
$1090 \mu \mathrm{m}$; Romagosa (1998), com a mesma espécie, obteve resultados semelhantes, quando os ovócitos eram de tonalidade verde-clara, homogêneos e apresentavam na amostra inicial diâmetro de maior freqüência igual a $939 \mu \mathrm{m}$. Narahara et al. (1986) realizaram experimentos com a pirapitinga-do-sul (Brycon opalinus) e verificaram ovulação em fêmeas selecionadas que apresentavam ovócitos cinzentos ou cor-de-vinho e, na distribuição de freqüência porcentual dos diâmetros dos ovócitos, modas entre 1750 e $2000 \mu \mathrm{m}$. Para a piracanjuba, Brycon orbignyanus, Belmont (1994) observou diâmetro de maior freqüência igual a $1221 \mu \mathrm{m}$, em fêmeas que liberaram óvulos após o tratamento hormonal.

As fêmeas de piabanha, no momento da ovulação, liberaram ovócitos com diâmetro entre 1450 e
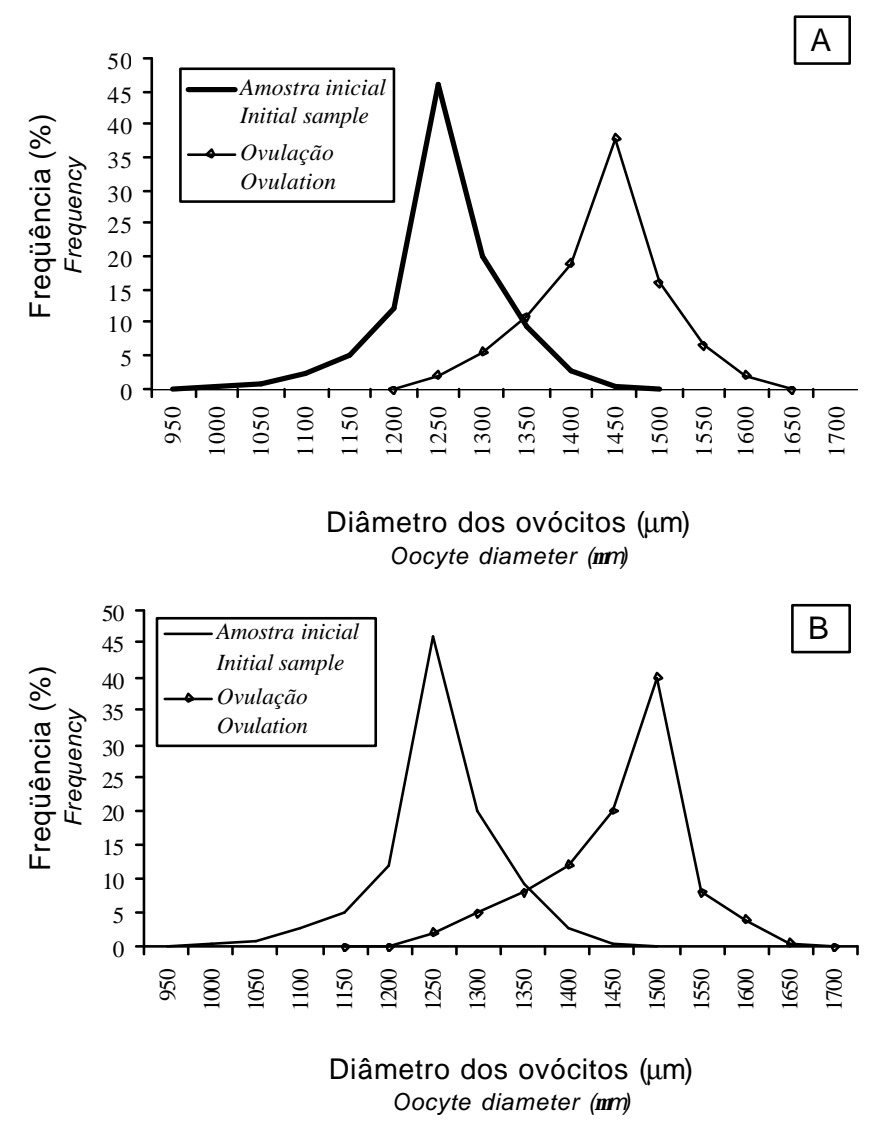

Figura 1 - Padrão de distribuição porcentual dos diâmetros dos ovócitos das fêmeas de piabanha Brycon insignis, induzidas à reprodução. A - taxa de fertilização inferior a $70 \%$. B - taxa de fertilização superior a $70 \%$.

Figure 1 - Pattern of oocytes diameter frequency distribution in females of Brycon insignis, induced to spawning. $A$ - fertilization rate lower than $70 \%$. $B$ - fertilization rate higher than $70 \%$. 
$1500 \mu \mathrm{m}$, aumentando 200 a $250 \mu \mathrm{m}$, o valor do diâmetro dos ovócitos da amostra inicial (Figuras $1 \mathrm{~A}$ e B). Aumento acentuado nos diâmetros dos ovócitos foi observado por Godinho et al. (1984), Romagosa et al. (1990) e Godinho et al. (1993), que utilizaram a análise do padrão de distribuição porcentual dos diâmetros dos ovócitos para identificar fêmeas aptas para serem induzidas a reprodução.

As 25 fêmeas que não responderam aos tratamentos hormonais apresentaram inicialmente distribuições de freqüência porcentual dos diâmetros dos ovócitos com modas inferiores ou superiores a 1250 $\mu \mathrm{m}$ e $33 \%$ delas, com distribuições bimodal ou polimodal, com modas entre 1200 e $1550 \mu \mathrm{m}$. O diâmetro médio dos ovócitos da primeira amostra variou entre 1205 e $1469 \mu \mathrm{m}$ e da terceira amostra, coletada 10 horas após a aplicação da última dose hormonal (tempo de latência), entre 1298 e $1582 \mu \mathrm{m}$. $\mathrm{Na}$ amostra final destas fêmeas foram observados ovócitos heterogêneos em coloração, variando entre verde, rósea e esbranquiçada.

Resultados semelhantes foram verificados por Fenerich-Verani et al. (1984) e Godinho et al. (1984), para o curimbatá, Prochilodus scrofa, e por Romagosa et al. (1990), para o pacu, Piaractus mesopotamicus. De acordo com Lam et al. (1978), ovócitos que atingiram diâmetros maiores que aqueles da ovulação, podem ou não ser eliminados e são denominados de "overripe"; quando eliminados, não são fertilizáveis, pois já entraram em processo de degeneração ou atresia. McEvoy (1984) confirma este fato, declarando que esses ovócitos são inviáveis.

Das 73 fêmeas de piabanha, induzidas à reprodução, cerca de $40 \%$ apresentaram ovócitos com núcleo central e $60 \%$ deslocados para a periferia (excêntrico). As 25 que não responderam ao tratamento hormonal mostraram, na amostra final, aproximadamente $25 \%$ dos ovócitos com núcleo central e $75 \%$ com núcleo excêntrico, sugerindo ação hormonal. $\mathrm{Na}$ amostra das 43 fêmeas que liberaram óvulos, não foi possível visualizar o núcleo.

De acordo com Lam (1982), o núcleo migra para um dos pólos do ovócito e se rompe momentos antes da ovulação. Brzuska \& Malczewski (1989) induziram a reprodução em Cyprinus carpio, quando a porcentagem de ovócitos com núcleo deslocado para a periferia era elevada. Narahara et al. (1986) obtiveram $35 \%$ de ovócitos de pirapitinga-do-sul, Brycon opalinus, com núcleo central e $65 \%$ com núcleo em posição excêntrica; Belmont (1994) verificou que fême- as de piracanjuba, Brycon orbignyanus, responderam ao tratamento hormonal quando $100 \%$ dos ovócitos apresentavam núcleo excêntrico, e Romagosa (1998) notou que fêmeas de matrinxã, Brycon cephalus, liberavam óvulos após a aplicação de hormônios indutores da reprodução quando $80 \%$ dos ovócitos da amostra inicial apresentava núcleo excêntrico.

Os reprodutores de piabanha mostraram comportamento agitado e agressivo; assim, após a aplicação hormonal, os reprodutores foram mantidos em aquários separados até o momento da extrusão. A mesma conduta foi adotada por Sato et al. (1997), com matrinchã, Brycon lundii.

Os machos selecionados liberaram sêmen de coloração branco-leitosa sob leve compressão da região ventral e, após 10 horas da última aplicação hormonal nas fêmeas, ocorreu a extrusão dos óvulos e a fertilização "a seco", de acordo com von Ihering \& Azevedo (1934).

As fêmeas de piabanha liberaram, em média, 24.690 óvulos, que, após a fertilização, se apresentaram esféricos, demersais, não adesivos, de coloração variando de verde-escura a verde-acastanhada. Após a hidratação, o diâmetro médio variou de 3785 a $3900 \mu \mathrm{m}$, evidenciando grande espaço perivitelínico envolto pelo córion bastante resistente. Bernardino et al. (1993) e Romagosa et al. (1994) observaram elevado grau de hidratação nos ovos de Brycon cephalus.

De acordo com Eddy (1984), para preservar o embrião, o córion dos ovos demersais de peixes de rio deve ser bem resistente para resistir ao estresse provocado pela ação do sedimento.

Considerando-se os tratamentos hormonais testados em piabanha, a taxa de fertilização variou entre 20 e $96 \%$ (média $76 \%$ ) e a de eclosão, entre 0 e $85 \%$ (média 42\%). Resultados semelhantes foram obtidos por Eckmann (1984), em Brycon cf erythropterus; Narahara et al. (1986), em Brycon opalinus, e por Romagosa (1998), em Brycon cephalus. Em Brycon orbignyanus, Belmont et al. (1994) observaram taxas de fertilização inferiores $(50 \%)$ e de eclosão próximas a 30\%, enquanto Zaniboni Filho \& Barbosa (1996) verificaram taxas de fertilização e de eclosão iguais a 12,8 e $10,5 \%$, respectivamente. Sato et al. (1997) obtiveram taxas de fertilização com valor médio de 50\%, para Brycon lundii.

As taxas de fertilização observadas nas fêmeas de piabanha induzidas a reprodução com hCG, foram, em média, maiores, quando comparadas com as obtidas nas fêmeas dos outros tratamentos. De acordo 
com Kjorsvik et al. (1990), a taxa de fertilização pode indicar a qualidade do ovo e, em óvulos não bem preparados, a ativação da reação cortical pode ser incompleta e resultar em pequeno espaço perivitelínico, comprometendo o desenvolvimento embrionário.

A temperatura exerce grande influência durante o desenvolvimento embrionário. Godoy (1975) observou que a eclosão de larvas de Salminus maxillosus ocorreu 22 horas e 52 minutos após a fertilização, a uma temperatura de $24^{\circ} \mathrm{C}$. Eckmann (1984) verificou em Brycon cf erythropterus que a eclosão ocorreu aproximadamente 16 horas após a fertilização, a $26,2^{\circ} \mathrm{C}$. Lopes et al. (1995) citam que, a $28-30^{\circ} \mathrm{C}$, o pacu (Piaractus mesopotamicus) e o tambaqui (Colossoma macropomum) eclodiram 12-14 horas após a fertilização, e quando a temperatura da água diminui para $25-26^{\circ} \mathrm{C}$, o tempo de desenvolvimento embrionário aumentou para 16-18 horas. Os mesmos autores ainda informam que, a uma temperatura média de $30^{\circ} \mathrm{C}$, o período de desenvolvimento embrionário de Brycon cephalus foi de 10 horas e 30 minutos. Para as larvas de piabanha, Brycon insignis, a eclosão ocorreu 14 horas após a fertilização, a $26 \pm 1^{\circ} \mathrm{C}$. Resultados semelhantes foram obtidos por Otero (1988), em Brycon moorei sinuensis.

Peixes que completam seu ciclo de vida em ambientes estáveis e se reproduzem através de desovas múltiplas, com ovos adesivos e prole assistida pelos pais, apresentam maior capacidade de adaptação às condições impostas pelas transformações dos ambientes lóticos em lênticos (Sargent et al., 1987; Lamas, 1993). Por outro lado, espécies de migração reprodutiva em época restrita do ano, que apresentam desova total por período, ovos livres que eclodem rapidamente e prole não assistida pelos pais, como a piabanha, devem ser melhor observadas, pois qualquer tipo de modificação do sistema hídrico pode provocar alterações na diversidade biológica.

\section{Conclusões}

A indução hormonal da piabanha (Brycon insignis) pode ser realizada em janeiro e fevereiro, a uma temperatura média da água de $26 \pm 1^{\circ} \mathrm{C}$.

A seleção de fêmeas pode basear-se na associação de características externas e internas: ventre abaulado, papila genital saliente e avermelhada; ovócitos homogêneos em cor e tamanho e de coloração verdeescura ou acastanhada; elevada porcentagem de ovócitos com núcleo em posição excêntrica (> ou = a
60\%); padrão de distribuição unimodal de freqüência porcentual dos diâmetros dos ovócitos (valor modal igual a $1250 \mu \mathrm{m})$.

A aplicação do hCG em dose única de $5 \mathrm{UI} / \mathrm{g}$ mostrou ser eficiente, induzindo à ovulação grande número de fêmeas.

As fêmeas liberaram, em média, 24.690 óvulos, sendo as taxas de fertilização e eclosão, $76 \%$ e $41,8 \%$, respectivamente. Estes dados estão de acordo com aqueles citados para outras espécies pertencentes ao mesmo gênero.

Os ovos hidratados são esféricos, demersais, não adesivos, com diâmetro médio de 3785 a $3900 \mu \mathrm{m}$ e grande espaço perivitelínico.

\section{Agradecimento}

A todos os funcionários da Estação Experimental da Seção de Hidrobiologia e Aqüicultura da CESP (Companhia Energética de São Paulo) - Paraibuna, São Paulo, pelo apoio técnico e pela acolhida carinhosa em suas dependências.

\section{Literatura Citada}

ANDRADE-TALMELLI, E. Indução reprodutiva e ontogenia inicial da piabanha, Brycon insignis (Steindachner, 1876) (Characiformes, Bryconinae), mantida em condições de confinamento - Vale do Paraíba, SP. São Carlos: Universidade Federal de São Carlos, 1997. 185p. Dissertação (Mestrado em Ecologia e Recursos Naturais) - Universidade Federal de São Carlos, 1997.

ANTONIUTTI, D.M.; NARAHARA, M.Y.; ROMAGOSA, E. Reprodução induzida e custo operacional de produção de alevinos de curimbatá Prochilodus scrofa (Steindachner, 1881). Boletim do Instituto de Pesca, v.22, n.1, p.41-47, 1995.

BELMONT, R.A.F. Considerações sobre a propagação artificial da piracanjuba, Brycon orbignyanus - CESP. In: SEMINÁRIO SOBRE CRIAÇÃO DE ESPÉCIES DO GÊNERO Brycon, 1., 1994. Pirassununga, Anais... São Paulo: Centro de Pesquisa e Treinamento em Aqüicultura, 1994. p.17-18.

BERNARDINO, G.; SENHORINI, J.A.; BOCK, C.L. et al. Propagação artificial do matrinchãBrycon cephalus (Günther, 1869) (Teleostei, Characidae). Boletim Técnico CEPTA, v.6, n.2, p.1-9, 1993.

BRZUSKA, E.; MALCZEWSKI, B. The effect of injection of carp (Cyprinus carpio L.) pituitary on maturation and ovulation of pike (Esoxlucius L.) oocytes.Acta Hydrobiológica, v.31, n.1/2, p.131-137, 1989.

ECKMANN, R. Induced reproduction in Brycon cf erythropterus. Aquaculture, v.38, p.379-382, 1984.

EDDY, F.B. Osmotic properties of the perivitelline fluid and some properties of the chorion of Atlantic salmon eggs (Salmo salar). Journal of Zoology, v.174, p.237-243, 1984.

FENERICH, N.A.; GODINHO, H.M.; BARKER, J.M.B. Sobre a ocorrência de ovulação de Rhamdia hilarii, Pimelodus maculatus, Salminus maxillosus, em laboratório. Ciência e Cultura, v.26, n.7, p.344, 1974. 
FENERICH-VERANI, N.; NARAHARA, M.Y.; GODINHO, H.M. The size composition of the eggs of curimbatá Prochilodus scrofa, Steind., 1881, induced to spawn with human chorionic gonadotropin (HCG). Aquaculture, v.42, p.37-41, 1984.

FOWLER, H.W. Os peixes de água doce do Brasil.Arquivos de Zoologia, v.6, p.333-340, 1950.

GERMAN, G.R. Mecanismos de inducción al desove utilizados en el cultivo de peces: Una Revision. Revista Latinoamericana de Acuicultura de Lima, v.43, p.55-102, 1994.

GIRARDI, L.; FARIA, C.A.; SANTOS, P.P. Reprodução induzida, larvicultura e alevinagem de piabanha Brycon insignis) na Estação de Aqüicultura de Paraibuna CESP/SP. In: ENCONTRO BRASILEIRO DE ICTIOLOGIA, 10., 1993, São Paulo. Anais... São Paulo: Sociedade Brasileira de Ictiologia, 1993. p.93.

GIRARDI, L.; SANTOS, P.P.; FARIA, C.A. Repovoamento com Brycon cf reinhardti (pirapitinga do sul) em tributários do reservatório da UHE de Paraibuna/Paraitinga, CESP, São Paulo. In: ENCONTRO BRASILEIRO DE ICTIOLOGIA, 11., 1995, PUC, Campinas, SP. Anais... Campinas: Sociedade Brasileira de Ictiologia, 1995. p.14.

GODINHO, H.M.; ROMAGOSA, E.; CESTAROLLI, M.A. et al. Reprodução induzida do curimbatá, Prochilodus scrofa, Steind. 1881 sob condições de cultivo experimental. Revista Brasileira de Reprodução Animal, v.8, n.2, p.113-119, 1984.

GODINHO, H.M.; KAVAMOTO, E.T.; ANDRADETALMELLI, E. et al. Induced spawning of the mullet Mugil platanus GÜNTHER, 1880, in Cananéia, São Paulo, Brazil. Boletim do Instituto de Pesca, v.20, n.(único), p.59-66, 1993.

GODOY, M.P. Peixes do Brasil. Subordem Characoidei. Bacia do Rio Mogi-Guassú. Piracicaba: São Paulo: Franciscana, 1975. v.2. p. 217-398.

GREELEY Jr., M.S.; CALDER, D.R.; WALLACE, R.A. Oocyte growth and development in the striped mullet, Mugil cephalus, during seasonal ovarian recrudescence: relationship to fecundity and size at maturity. Fishery Bulletin, v.85, n.2, p.187-200, 1987.

HARVEY, B.J.; HOAR, W.S. The theory and practice of induced breeding in fish. Ottawa, CIID, 1980. 48p.

HARVEY, B.J.; CAROLSFELD, J. Induced breeding in tropical fish culture. Ottawa: I.D.R.C., 1993. 144p.

HOWES, G. Review of the genus Brycon (Teleostei-Characoidei). Bulletin of British Museum of Natural History (Zoology), v.43, n.1, p.1-47, 1982.

JALABERT, B.; BRETON, B.; BRZUSKA, E. et al. A new tool for induced spawning: the use of 17a-hydroxy- 20bdihydroprogesterone to spawn carp at low temperature. Aquaculture, v.10, p.353-364, 1977.

KJORSVIK, E.; MANGOR-JENSEN, A.; HOLMEFJORD, I. Egg quality in fishes. Advances in Marine Biology, v.26, p.71-113, 1990.

KUO, C.M.; NASH, C.E. Recent progress on the control of varian development and induced spawning of the grey mullet (Mugil cephalus L.) Aquaculture, v.5, p.19-29, 1975.

LAM, T.J.; NAGAHAMA, Y.; CHAN, K. et al. Overripe eggs and postovulatory corporea lutea in the threespine stickleback, Gasterosteus aculeatus L. form trachurus. Canadian Journal of Zoology, v.56, p.2029-2036, 1978.

LAM, T.J. Applications of endocrinology to fish culture. Canadian Journal of Fisheries and Aquatic Sciences, v.39, p.111-137, 1982.

LAMAS, I.R. Análise de características reprodutivas de peixes brasileiros de água doce, com ênfase no local de desova. Belo Horizonte: Universidade Federal de Minas Gerais, 1993. 72p. Dissertação (Mestrado) - Universidade Federal de Minas Gerais, 1993.

LEMANOVA, N.A.; SAKUN, O.F. Metodisceskoe posibie pogor monalnoi stimulacji proizvoditielei karpa pré rannom polucenii licinok. Izvestiya Gosudartvennogo Nauchno Issledivatel Skogo Instituta, v.88, p.3-23, 1975.

LIMA, J.A.F.; ARANTES, C.F.S.; PADOVANI, R. Observações preliminares sobre o crescimento heterogêneo (HET-G) da piracanjuba, Brycon orbignyanus, em tanques rede. In: ENCONTRO BRASILEIRO DE ICTIOLOGIA, 11., 1995. Campinas. Anais... Campinas: Sociedade Brasileira de Ictiologia, 1995. p.Q6.

LIMA, F.C.T.; BRITSKI, H.A. Revisão das espécies do gênero Brycon MÜLLER; dos Rios do Sudeste da América do Sul (Characiformes; Characidae). In: ENCONTRO BRASILEIRO DE ICTIOLOGIA, 12., 1997, São Paulo, Resumos... São Paulo: Sociedade Brasileira de Ictiologia, 1997. p.89.

LOPES, R.N.M.; SENHORINI, J.A.; SOARES, M.C.F. Desenvolvimento embrionário e larval do matrinxã, Brycon ceplalus Günther, 1869 (Pisces, Characidae). Boletim Técnico do CEPTA, v.8, p.25-39, 1995.

MACHADO, C.E.M.; ABREU, E.C.F. Notas Preliminares sobre a caça e a pesca no Estado de São Paulo - I) A Pesca no Vale do Paraíba. Boletim de Indústria Animal, v.13, p.145-160, 1952.

McEVOY, L.A. Ovulatory rhythms and over-ripening of eggs in cultivated turbot, Scophthalmus maximus L. Journal of Fish Biology, v.24, p.437-448, 1984.

MENDONÇA, J.O.J.; SENHORINI, J.A.; FONTES, N.A. Influência da fonte protéica no crescimento do matrinchã Brycon cephalus, em viveiros. Boletim Técnico do CEPTA, v.6, n.1, p.51-58, 1993.

MENDONÇA, J.O.J. Criação de espécies do gênero Brycon no CEPTA/IBAMA. In: SIMPÓSIO SOBRE CRIAÇÃO DE ESPÉCIES DO GÊNERO Brycon, 1., 1994, Pirassununga. Anais... São Paulo: Centro de Pesquisa e Treinamento em Aqüicultura, 1994. p.17-18.

NARAHARA, M.Y.; KAVAMOTO, E.T.; GODINHO, H.M. et al. Observações preliminares sobre a reprodução induzida da pirapitinga do sul, Brycon sp. In: CONGRESSO BRASILEIRO DE ZOOLOGIA, 13., 1986, Cuiabá.Anais... Cuiabá: Sociedade Brasileira de Zoologia, 1986. p.150.

NARAHARA, M.Y.; ANDRADE, E.F.; GODINHO, H.M. et al. Tipo de desova da pirapitinga do sul, Brycon sp. In: CONGRESSO BRASILEIRO DE ZOOLOGIA, 14., 1987, Juiz de Fora. Anais... Juiz de Fora: Sociedade Brasileira de Zoologia, 1987. p.90.

NARAHARA, M.Y.; ANDRADE, E.F.; GODINHO, H.M. Fecundidade de pirapitinga do sul Brycon sp, mantida sob condições experimentais de cultivo intensivo. In: CONGRESSO BRASILEIRO DEZOOLOGIA, 15., 1988, Curitiba. Anais... Curitiba: Sociedade Brasileira de Zoologia, 1988. p.371.

NARAHARA, M.Y.; KAVAMOTO, E.T.; GODINHO, H.M. et al. Pesquisas sobre a criação do gênero Brycon, no Instituto de Pesca. In: SEMINÁRIO SOBRE A CRIAÇÃO DE ESPÉCIES DO GÊNERO Brycon, 1., 1994, Pirassununga. Anais... Pirassununga: 1994. p.5-6.

OTERO, R. Reprodución y técnicas de propagación de la dorada 
Brycon moore sinuensis, Dahl, 1955. In: REUNION RED NACIONAL DE ACUICULTURA, 2., 1988, Nerva. Memórias... Nerva: 1988. p.157-168.

PEREIRA FILHO, M.; CASTAGNOLLI, N.; GRAEF, E.W. et al. Protein and crude fiber level in diets for young matrinchã (Brycon cephalus), an Amazonian fish.Aquaculture, v.124, n.1/4, p.66, 1994.

PIOVESAN, U.; DIAZ, T.C.R.; CASTAGNOLLI, N. Efeito da dieta na sobrevivência de larvas de piracanjuba Brycon orbignyanus). In: SIMPÓSIO BRASILEIRO DE AQÜICULTURA; ENCONTRO BRASILEIRO DE PATOLOGIA DE ORGANISMOS AQUÁTICOS, 3., 1994, Piracicaba. Anais... Piracicaba: 1994. p. 81.

ROMAGOSA, E.; AYROSA, L.M.S.; SANCHES, E.G. et al. Informes preliminares sobre a reprodução induzida do matrinchã, Brycon cephalus. In: SIMPÓSIO BRASILEIRO DE PESQUISAS EM MEDICINA VETERINÁRIA, 1., 1994, São Paulo. Resumos... São Paulo, 1994. p.111.

ROMAGOSA, E.; PAIVA, P.; GODINHO, H.M. Pattern of oocytes diameter frequency distribution in females of the pacu, Piaractus mesopotamicus (Holmberg, 1887) (= Colossoma mitrei Berg, 1895) induced to spawn. Aquaculture, v.86, p.105-110, 1990.

ROMAGOSA, E. Desenvolvimento gonadal (morfologia; ultra-estrutura) e indução da reprodução do matrinchã, Brycon cephalus (Günther, 1869) em cativeiro Vale do Ribeira. São Carlos: Universidade Federal de São Carlos, 1998. 218p. Tese (Doutorado em Ecologia e Recursos Naturais) - Universidade Federal de São Carlos, 1998.

SAlGADO, A.F.G.; CHAIN, M.G.; GIRARDI, L. et al. A conservação da piabanha (Brycon insignis) na Bacia do Rio Paraíba do Sul. São Paulo: 1997. 28p. (Relatório Técnico-CESP).
SARGENT, R.C.; TAYLOR, P.D.; GROSS, M.R. Parental care and the evolution of egg size in fishes.American Naturalist, v.129, n.1, p.98-102, 1987.

SATO, Y.; FENERICH-VERANI, N.; GODINHO, H.P. et al. Reprodução induzida do matrinchã (Brycon lundii) REINHARDTI, 1877, da Bacia do Rio São Francisco. In:SEMINÁRIO REGIONAL DE ECOLOGIA, 7., 1997, São Carlos. Anais... São Carlos: Universidade Federal de São Carlos, 1997. p.353-359.

SIMPSON, A.C. The fecundity of the plaice. Fishery Investigation, v.5, n.17, p.1-27, 1951.

Von IHERING, R.; AZEVEDO, P. A curimatã dos açudes nordestinos (Prochilodus argenteus). Archivos do Instituto Biológico, v.5, p.143-184, 1934.

WALLACE, R.A.; SELMAN, K. Cellular and dynamic aspects of oocyte growth in teleosts. American Zoologist, v.21, p.325-343, 1981.

WEST, G. Methods of assessing ovarian development in fishes: a review. Australian Journal of Marine and Freshwater Research, v.41, p.199-222, 1990.

ZANIBONI FILHO, E.; BARBOSA, N.D.C. Priming hormone administration to induce spawning of some Brazilian migratory fish. Revista Brasileira de Biologia, v.56, n.4, p.655-659, 1996.
Recebido em: 19/06/01

Aceito em: 12/12/01 